Article

\title{
Inhibition of Poly(ethylenediaminetetraacetic acid-diethanolamine) on Deposition of Calcium Sulfate Crystal in Simulated Industrial Water
}

\author{
Jian-Qiu Chen, Ting-Ran Liu, Miao-Miao Sun, Yu-Zeng Zhao * ${ }^{-}$and Hong-Hua Ge * \\ Shanghai Engineering Research Center of Energy-Saving in Heat Exchange Systems, Shanghai Key Laboratory \\ of Materials Protection and Advanced Materials in Electric Power, Shanghai University of Electric Power, \\ Shanghai 200090, China; chenjq666888@163.com (J.-Q.C.); liutingran@163.com (T.-R.L.); \\ sunmiao_927@163.com (M.-M.S.) \\ * Correspondence: zhaoyuzeng@shiep.edu.cn (Y.-Z.Z.); gehonghua@shiep.edu.cn (H.-H.G.); \\ Tel.: +86-021-61655175 (H.-H.G.)
}

Received: 9 May 2020; Accepted: 19 June 2020; Published: 25 June 2020

\begin{abstract}
Calcium sulfate scale is a typical deposit on the equipment pieces or pipes of an industrial water system. Scale inhibitors could obviously reduce the precipitation of calcium sulfate crystal. The development and research of late-model environmentally friendly polymer inhibitors are often urgent problems to be addressed. A water-soluble poly(ethylenediaminetetraacetic acid-diethanolamine) (PEDTA-DEA) was successfully synthesized by thermal polycondensation of ethylenediaminetetraacetic acid (EDTA) with diethanolamine (DEA). The polymer product was characterized by Fourier infrared spectrum (FTIR) and the molecular weight was measured by gel chromatography, which confirms the polymerization of the two monomers. The inhibition effect of the polymer against calcium sulfate deposition was studied by static scale inhibition tests. When the $\mathrm{Ca}^{2+}$ concentration is $3000 \mathrm{mg} / \mathrm{L}$, and the dosage of the polymer inhibitor is $10 \mathrm{mg} / \mathrm{L}$, the inhibition effect exceeds $90 \%$. The results show that PEDTA-DEA can inhibit the precipitation of calcium sulfate and reduce the deposition of calcium sulfate scale. The precipitate of calcium sulfate collected from the static scale inhibition test solution was analyzed by FTIR, scanning electron microscope (SEM) and $\mathrm{X}$-ray diffraction (XRD). The results revealed that the addition of the polymer significantly changes the calcium sulfate crystal's growth shape. Therefore, PEDTA-DEA is a potential calcium sulfate precipitation inhibitor for the industrial water system.
\end{abstract}

Keywords: calcium sulfate; polymer scale inhibitor; ethylenediaminetetraacetic acid; diethanolamine

\section{Introduction}

Water is often used as the heated fluid in the industrial water system because of its large specific heat capacity [1-3]. Due to the evaporation of water, scaling ions, such as calcium and magnesium ions, combine easily with carbonate or sulfate ions $[4,5]$ and then form a low-soluble scale precipitating on the surface of equipment pieces and pipes. As a result, the equipment pieces and pipes become severely corroded and blocked by calcium scale and may even burst [6,7]. Calcium carbonate scale can be easily removed by acid treatment, but once calcium sulfate is formed, removal becomes difficult $[8,9]$. Therefore, it is necessary to reduce the deposition of calcium sulfate scale in the industrial water system. Using a scale inhibitor is one of the most effective and straightforward methods [10].

Synthetic water-soluble polymer scale inhibitors are most widely used in industry, including acrylic polymers [11,12], malefic polymers [13,14], sulfonic acid polymers [15-17] and phosphorus-containing polymers [18-20]. However, there are also many drawbacks in terms of environmental protection. For example, some scale inhibitors can cause eutrophication of water, or cannot be biodegraded. 
Environmentally friendly scale inhibitors have been widely researched and developed with the improvement of public environmental awareness and stricter environmental laws and regulations. The most commonly applied green scale inhibitors are poly(aspartic acid) and its derivatives [21-23], as well as polyepoxysuccinic acid and its derivatives [12,24,25]. They are not cost-effective, despite their environmental friendliness and good scale-inhibition effect. Zhao [26] has developed a kind of polymer inhibitor synthesized from citric acid as a monomer. The inhibition performance against $\mathrm{CaSO}_{4}$ scale is excellent. When the dosage of scale inhibitor is $25 \mathrm{mg} / \mathrm{L}$, the scale inhibition rate is as high as $98.8 \%$. However, the scale inhibition performance for $\mathrm{CaCO}_{3}$ scale is not good enough. Only when the usage of scale inhibitor reaches $100 \mathrm{mg} / \mathrm{L}$, does the scale inhibition rate reach $87 \%$. Therefore, the development of an up-to-date, environmentally friendly and cost-effective polymer scale inhibitor is currently a focus research.

Most of those polymer inhibitors contain the carboxylic acid (-COOH) group which plays an essential role in the scale inhibition of calcium carbonate and calcium sulfate. In order to obtain the new type of polymer containing suspended carboxylic groups, the selected monomer should also contain multiple carboxylic groups. Ethylenediaminetetraacetic acid (EDTA) contains four carboxylic groups in each of its molecules. It is a non-toxic and harmless compound used as a food additive $[27,28]$, etc. But EDTA has little scale inhibition against $\mathrm{CaSO}_{4}$ scale and it cannot be used as an inhibitor directly. According to the report [26], the scale inhibition of small molecules gets worse. However, it could be increased through polymerizing small molecules to generate a polymer. The carboxylic acid group can be chemically reacted with the hydroxyl group or amine group to form ester or amide bonds, respectively. Therefore, as a kind of multi-carboxyl molecule, EDTA could be subjected to condensation polymerization with diol or diamine to synthesize a high molecular polymer. Calcium sulfate is a kind of common scale, which often appears in circulating cooling water systems [29], seawater desalination systems [30-32] and oilfield water injection systems [13,33]. In order to solve this problem, scale inhibitor has come into being.

In this paper, a new polymer, poly(ethenediaminetetraacetic acid-diethanolamine) (PEDTA-DEA) was prepared by virtue of polycondensation with EDTA and diethanolamine (DEA) as monomers. The inhibition of the polymer against calcium sulfate crystal precipitation was further estimated by the static scale inhibition test and the inhibition performance in different test conditions was evaluated in simulated industrial water.

\section{Materials and Methods}

\subsection{Materials}

The EDTA, DEA, calcium chloride and sodium sulfate used in the experiment are all analytically pure and were purchased at Shanghai Lingfeng Chemical Reagent Co. Ltd., in China. Commercial scale inhibitors, hydroxyethylenediphosphonic acid (HEDP), 2-phosphonbutane-1,2,4-tricarboxylic acid (PBTCA) and polyaspartic acid (PASP, $4000 \mathrm{Da}$ ) were provided by the Shanghai Duojia Water Treatment Company in China and are all industrially pure. All of the reagents were used directly without further purification.

\subsection{Synthesis of Polymer}

The typical synthesis process is stated as follows. $2.92 \mathrm{~g}$ EDTA and $1.0 \mathrm{~mL}$ DEA were placed in a three-neck, round-bottom flask with a 1:1 molar ratio, with $10 \mathrm{~mL}$ of $\mathrm{N}, \mathrm{N}$-dimethylformamide as solvent, and $5 \mathrm{~mL}$ phosphoric acid as catalyst dropped into the round-bottom flask. The flask was kept at $200{ }^{\circ} \mathrm{C}$ for $2 \mathrm{~h}$. Then the resulting reaction product was solved in deionized water. We adjusted the $\mathrm{pH}$ of the solution to neutral (between 6 and 8 ) with a $5 \mathrm{~mol} / \mathrm{L}$ sodium hydroxide solution. At last, the solution was dialyzed by a dialysis membrane (retaining molecular weight $>1000$ macromolecules). The desired product polymer was obtained from the retained solution by rotary evaporation, which was subsequently dried in vacuum at $50^{\circ} \mathrm{C}$ for $24 \mathrm{~h}$. 


\subsection{Characterization of the Prepared Polymers}

Fourier transformation infrared (FTIR) spectra were obtained by attenuated total reflection (ATR) method on a Spectrum Two spectrometer (FTIR-8400 S, Shimadzu Co. Ltd., Japan). Alongside, size exclusion chromatography (Agilent 1260, Agilent Ltd., Palo Alto, Santa Clara, CA, USA) was used to determine the molecular weight of the polymers by using polyethylene glycol as the standard and deionized water as the fluent phase.

The hydrogen nuclear magnetic resonance $\left({ }^{1} \mathrm{HNMR}\right)$ spectra were obtained at ambient temperature for the reagent solution in the 5-mm-diameter sample tubes on Bruker AVANCE spectrometer (Bruker Bio Spin GmbH., Baden-Wurttemberg, Germany). The reagent solution was DMSO- $\mathrm{d}_{6}$. The stability of the polymer was analyzed by thermogravimetric (TG) analysis (NETZSCH STA 449F3, NETZSCH-Gerätebau GmbH., Selb, Germany). The temperature range for testing was $25-600{ }^{\circ} \mathrm{C}$, and the whole process was carried out in a nitrogen atmosphere. The heating rate was $10^{\circ} \mathrm{C} / \mathrm{min}$.

\subsection{Evaluation of Polymer Inhibition Performance of Precipitation}

The scale inhibition performance was evaluated by a static scale inhibition test according to the Standards for Petroleum and Natural Gas Industry of the People's Republic of China Q/SY126-2014. The $50 \mathrm{~mL}$ test solution contained $3000 \mathrm{mg} / \mathrm{L} \mathrm{Ca}^{2+}$ (made by calcium chloride), $3000 \mathrm{mg} / \mathrm{L} \mathrm{SO}_{4}{ }^{2-}$ (made by sodium sulfate) and a certain amount of the prepared polymer inhibitor. The test solution was placed in a water bath at $80^{\circ} \mathrm{C}$ for $10 \mathrm{~h}$. Then the solution was filtered after being cooled to room temperature. We accurately measured $10.00 \mathrm{~mL}$ filtrate, and added two drops of chrome black $\mathrm{T}$ indicator and $1.0 \mathrm{~mL}$ ammonia-ammonium chloride buffer solution. The calcium in the solution was titrated with $0.1 \mathrm{~mol} / \mathrm{L}$ of ethylenediaminetetraacetie disodium (EDTA-Na) standard solution. The inhibition ratio was calculated by the following Equation (1).

$$
\eta_{s}=\frac{V_{2}-V_{1}}{V_{0}-V_{1}} \times 100 \%
$$

where $V_{0}$ is the consumption volume of the EDTA-Na standard solution to titrate the blank solution without inhibitor. $V_{1}$ is the consumption volume of the EDTA-Na standard solution to titrate the mixed solution without inhibitor, kept at $80^{\circ} \mathrm{C}$ for $10 \mathrm{~h} . V_{2}$ is the consumption volume of the EDTA standard solution to titrate the mixed solution with inhibitor, kept at $80^{\circ} \mathrm{C}$ for $10 \mathrm{~h}$.

Similarly, the scale inhibition performance was evaluated according to the national standard of China numbered GB/T 16632-2008 (named "Determination of Scale-Inhibition Performance of Water Treatment Agents-Calcium Carbonate Precipitation Method"). There was $240 \mathrm{mg} / \mathrm{L} \mathrm{Ca}^{2+}$ (made by calcium chloride), $732 \mathrm{mg} / \mathrm{L} \mathrm{HCO}_{3}{ }^{-}$(made by sodium bicarbonate) and a certain amount of the prepared polymer inhibitor contained in the solution. The test solution was placed in a water bath $80^{\circ} \mathrm{C}$ for $10 \mathrm{~h}$, and we maintained the initial $\mathrm{pH}$ of the solution at 9.0 under borax buffer. Then the solution was filtered after it was cooled to room temperature. $10.00 \mathrm{~mL}$ filtrate was accurately measured, followed by adding two drops of chrome black $\mathrm{T}$ indicator as well as $1.0 \mathrm{~mL}$ of ammonia-ammonium chloride buffer solution. The calcium in the solution was titrated with $0.01 \mathrm{~mol} / \mathrm{L}$ of ethylenediaminetetraacetie disodium (EDTA-Na) standard solution. The inhibition ratio was calculated by the Equation (2) as follows.

$$
\eta_{s}=\frac{V_{2}-V_{1}}{V_{0}-V_{1}} \times 100 \%
$$

where $V_{0}$ is the consumption volume of the EDTA-Na standard solution to titrate the blank solution without inhibitor. $V_{1}$ is the consumption volume of the EDTA-Na standard solution to titrate the combined solution without inhibitor, kept at $80^{\circ} \mathrm{C}$ for $10 \mathrm{~h} . V_{2}$ is the consumption volume of the EDTA standard solution to titrate the mixed solution including inhibitor, kept at $80^{\circ} \mathrm{C}$ for $10 \mathrm{~h}$. 


\subsection{The Morphology of the Calcium Sulfate Crystal Precipitation}

Calcium sulfate crystal obtained from the static scale inhibition experiment was sprayed with a sputter-thin, gold film onto the surface of the precipitation particles. Then the particles were observed by a scanning electron microscope (SEM) at an accelerating voltage of $15 \mathrm{kV}$. The X-ray diffraction (XRD) mode of the calcium sulfate powder was recorded with the aid of copper $\mathrm{K} \alpha$ radiation using a D8 advanced X-ray diffractometer (Bruker AXS GmbH, Karlsruhe, Germany).

\section{Results and Discussion}

\subsection{Structure of Prepared Polymers}

The condensation polymerization may occur between carboxyl groups of EDTA and the hydroxyl groups or amine groups of DEA (as shown in Figure 1). There are four carboxyl groups in each EDTA molecule (see Figure 1a), and two hydroxyl groups and one amine group in each DEA molecule (see Figure 1b). According to chemical principles, an esterification reaction occurs between a carboxyl group and a hydroxyl group or an amidation reaction occurs between a carboxyl group and an amine group, catalyzed by acid or base as a catalyst. Thus, EDTA and DEA can be thermally polycondensed to produce polymers. As mentioned above, the configuration of the polymer is not necessarily a mono-linear polymerization, but may be branched. The polymer presented in Figure 1 consists of a plurality of carboxyl groups, and can continue to react to form an ester bond or an amide bond. In short, there are many carboxyl, ester and amide groups in PEDTA-DEA.

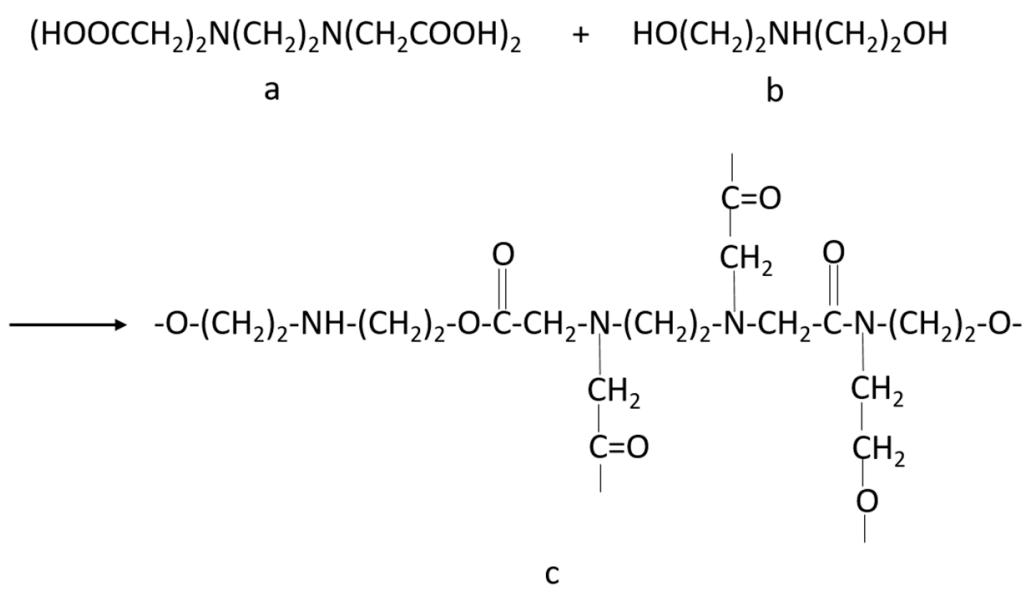

Figure 1. Molecular structure of ethylenediaminetetraacetic acid (EDTA) (a), diethanolamine (DEA). (b) and possible fragments of poly(ethylenediaminetetraacetic acid-diethanolamine) (PEDTA-DEA) (c).

Infrared spectra of EDTA and DEA are obviously different from the polymer products. In the infrared spectrum of EDTA (curve a in Figure 2A), the stretching vibration peaks of $-\mathrm{CH}_{2}$ - are $3017 \mathrm{~cm}^{-1}$ and $1439 \mathrm{~cm}^{-1}$ and the $\mathrm{C}=\mathrm{O}$ bond in the carboxylic acid group is $1683 \mathrm{~cm}^{-1}$. The peak at $1388 \mathrm{~cm}^{-1}$ is the C-N bond, $1310 \mathrm{~cm}^{-1}$ is the bending vibration of the $\mathrm{C}-\mathrm{C}$ bond and $765 \mathrm{~cm}^{-1}$ is the stretching vibration peak of the $\mathrm{C}-\mathrm{O}$ bond in $\mathrm{C}-\mathrm{OH}$. In the infrared spectrum of DEA (curve b in Figure 2A), $3296 \mathrm{~cm}^{-1}$ is the stretching vibration peak of $-\mathrm{OH}$ while $2837 \mathrm{~cm}^{-1}$ is the stretching vibration peak of $-\mathrm{CH}_{2}$ - $-\mathrm{NH}$ - bond vibration peaks are at $1453 \mathrm{~cm}^{-1}$ (in-plane bending) and $861 \mathrm{~cm}^{-1}$ (out-of-plane vibration), respectively. The in-plane bending vibration peak of the $\mathrm{O}-\mathrm{H}$ bond is $1361 \mathrm{~cm}^{-1}, 1122 \mathrm{~cm}^{-1}$ is the stretching vibration peak of the $\mathrm{C}-\mathrm{N}$ bond and $1050 \mathrm{~cm}^{-1}$ is the stretching vibration peak of the $\mathrm{C}-\mathrm{O}$ bond. In the infrared spectrum of the polymer (curve $\mathrm{c}$ in Figure 2A), the stretching vibration peak of $-\mathrm{CH}_{2}$ - is at $2975 \mathrm{~cm}^{-1}$ and $1501 \mathrm{~cm}^{-1}$. The peaks at $1654 \mathrm{~cm}^{-1}$ and $1648 \mathrm{~cm}^{-1}$ are the carbonyl groups in the suspension carboxylic - $\mathrm{COOH}$, amide groups $\mathrm{R}-\mathrm{CO}-\mathrm{NR}_{2}$ and ester groups -CO-O-. Moreover, the vibration peak of the $\mathrm{C}-\mathrm{O}$ bond in the carbonyl group is at $1466 \mathrm{~cm}^{-1}$. 
Comparing the three infrared spectra in Figure 2A, the newly generated peak at $1397 \mathrm{~cm}^{-1}$ is the stretching vibration peak of the C-N-C bond and the peak at $1167 \mathrm{~cm}^{-1}$ is the stretching vibration peak of the $\mathrm{C}-\mathrm{N}$ in the amide bond (curve $\mathrm{c}$ in Figure 2A). Simultaneously, the intensity of the peaks of $-\mathrm{C}-\mathrm{O}-(\mathrm{H})$ and $-\mathrm{NH}-$ in curve $\mathrm{c}$ of Figure $2 \mathrm{~A}$ are both weaker than that of the peaks in curve a and curve $\mathrm{b}$ of Figure 2A. It can be known these groups will reduce when the polymer is formed, all of which indicate that the two monomers have successfully transferred into the polymer.

The ${ }^{1} \mathrm{H}$ NMR was recorded on Bruker AVANCE spectrometer (as shown in Figure 2B-D). Chemical shifts $(\delta)$ were expressed in ppm relative to the residual of solvent (DMSO 2.5 ppm for ${ }^{1} \mathrm{H}$ NMR). Coupling constants (J) were recorded in hertz (Hz). Multiplicities explained by the following abbreviations: s, singlet; $d$, doublet; $t$, triplet; $q$, quartet.

${ }^{1} \mathrm{H}$ NMR (500 MHz, DMSO-d $\left.{ }_{6}, \delta\right)$ : EDTA: $2.76(\mathrm{~s}, 4 \mathrm{H}) ; 3.33(\mathrm{~s}, 8 \mathrm{H}) ; 3.45$ (s, 4H). DEA: 2.56 $\left(\mathrm{t}, \mathrm{J}_{1}=10 \mathrm{MHz}, 4 \mathrm{H}\right) ; 3.43\left(\mathrm{t}, \mathrm{J}_{2}=0.5 \mathrm{MHz}, 4 \mathrm{H}\right) ; 3.84(\mathrm{~s}, 3 \mathrm{H})$. PEDTA-DEA: $2.86\left(\mathrm{~d}, \mathrm{~J}_{3}=80 \mathrm{MHz}\right.$, the peak of $\mathrm{H}$ in the unreacted carboxyl group); $2.96\left(\mathrm{~d}, \mathrm{~J}_{4}=55 \mathrm{MHz}\right.$, the peak of $\mathrm{H}$ in the methylene group linked to the carboxyl group.); 3.56 (s, the peak of $\mathrm{H}$ in amino group).

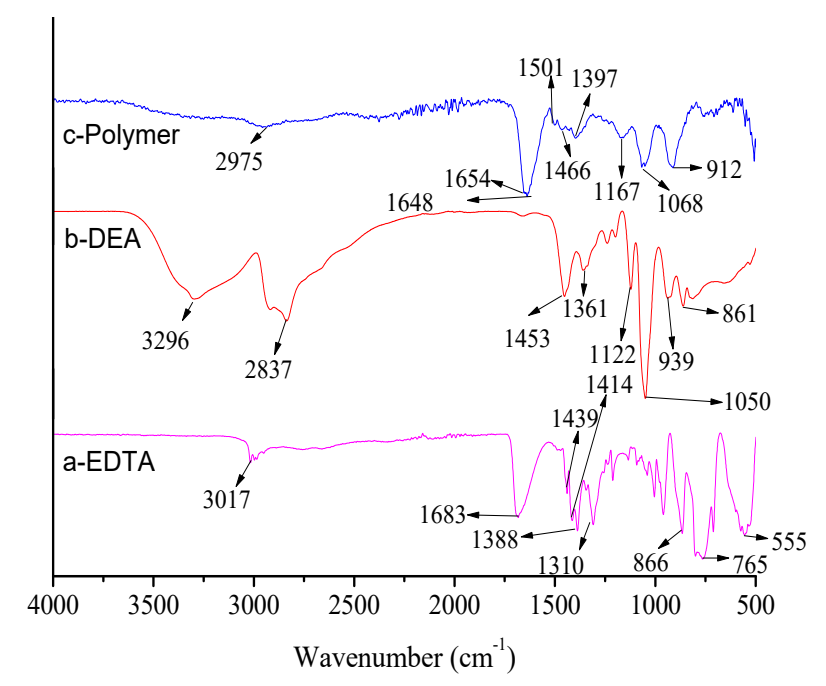

(A)

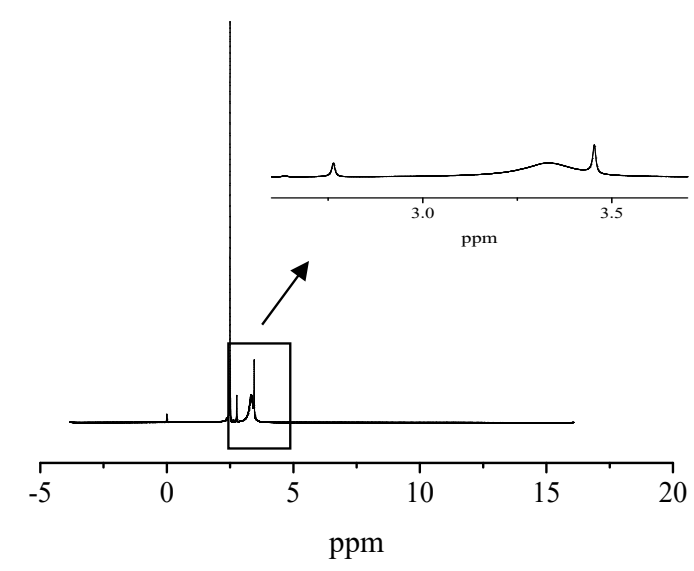

(B)

Figure 2. Cont. 


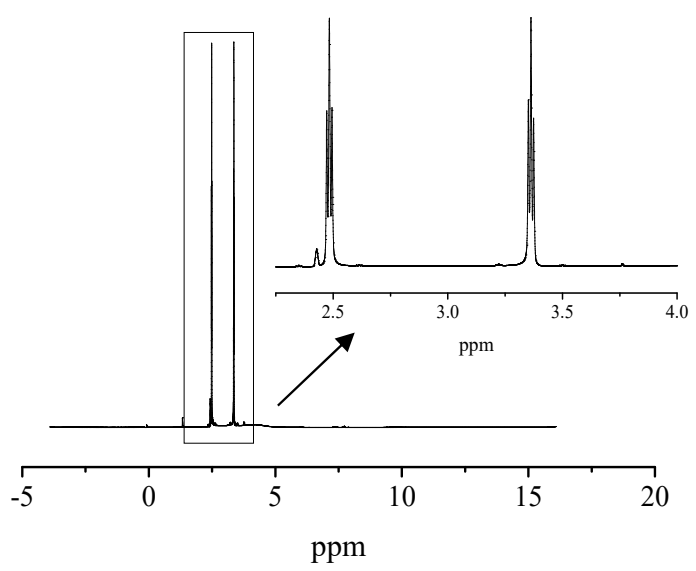

(C)

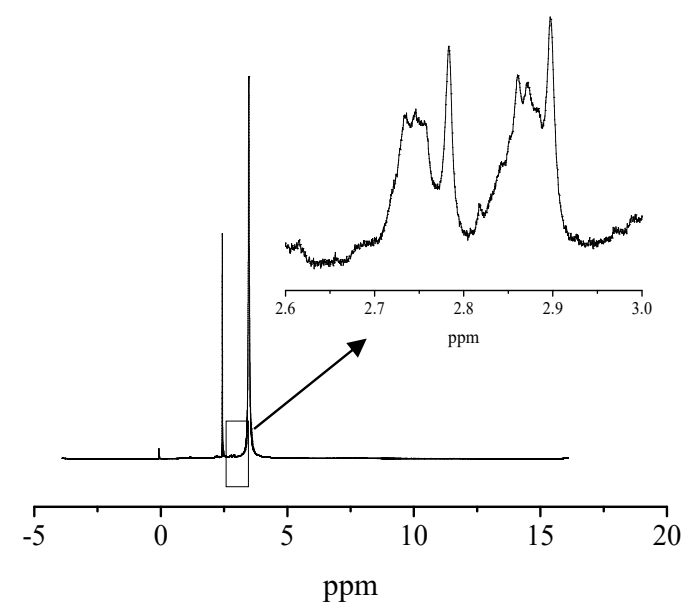

(D)

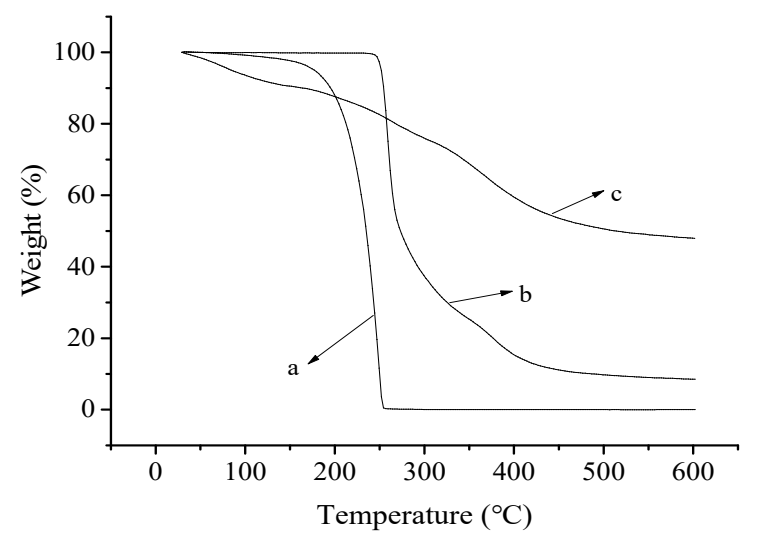

(E)

Figure 2. (A) The Fourier infrared spectrum (FTIR) spectra of the EDTA (a), DEA (b) and PEDTA-DEA (c). (B) ${ }^{1} \mathrm{H}$ NMR spectra of EDTA in DMSO-d 6 . (C) ${ }^{1} \mathrm{H}$ NMR spectra of DEA in DMSO-d 6 . (D) ${ }^{1} \mathrm{H}$ NMR spectra of PEDTA-DEA in DMSO-d . (E) The stability analysis of DEA (a), DETA (b) and PEDTA-DEA (c). 
The stability of the polymer was determined by thermogravimetry and the results are shown in Figure 2E. When the test temperature of thermogravimetric analysis (TGA) is at the range of $100{ }^{\circ} \mathrm{C}-200{ }^{\circ} \mathrm{C}$, the stability of the polymer is similar to that of the raw material. When the temperature is over $250^{\circ} \mathrm{C}$, the polymer is much more stable than EDTA and DEA. The highest temperature used in this experiment was $180^{\circ} \mathrm{C}$, so PEDTA-DEA has good stability.

The molecular weight of the polymer is measured by size exclusion chromatography. The number average molecular weight $(\mathrm{Mn})$ of the PEDTA-DEA was $1.97 \times 10^{4} \mathrm{Da}$, and the polydispersity coefficient of the polymer was 1.4. All of these illustrate that the condensation polymerization was carried out efficaciously.

\subsection{Precipitation Inhibition Performance of Prepared Polymers}

The precipitation inhibition of the prepared polymers was evaluated by a static scale inhibition test. It can be observed that all of the polymers have distinct inhibition performance against calcium scale crystal precipitation. When the dosage of the polymer inhibitor is $20 \mathrm{mg} / \mathrm{L}$, the inhibition rate can reach $93.2 \%$, and the inhibition effect will not increase much as the dosage of polymer increases. Some of other inhibitors show similar performance to calcium sulfate $[8,23,34]$ and all manifested threshold effects.

The precipitation inhibition properties of the polymers are related to the types and amounts of functional groups on the polymer. The main functional group that is capable of inhibiting calcium sulfate may be a carboxylic acid group (-COOH) [26]. The molecular structure of the polymer is shown in Figure 1, and the molecular structures of PBTCA, HEDP and PASP are presented individually in Figure 3. Although prepared polymer and PBTCA molecules all have a large number of carboxylic acid groups, there are differences between the polymer, PBTCA and HEDP. Polymer molecules include ester groups (-CO-O-) and amide groups (-CO-NH-), compared with each PBTCA molecule with a phosphonate group $\left[-\mathrm{PO}(\mathrm{OH})_{2}\right]$ and three carboxylic groups. In a further step, HEDP has two phosphonate groups $\left[-\mathrm{PO}(\mathrm{OH})_{2}\right]$ and a hydroxyl group (-OH), EDTA has four carboxylic groups $(-\mathrm{COOH})$ and DEA has two hydroxyl groups $(-\mathrm{OH})$, respectively.<smiles>O=C(O)CCC(CC(=O)O)(C(=O)O)P(=O)(O)O</smiles>

a<smiles>CC(O)(P(=O)(O)O)P(=O)(O)O</smiles>

b<smiles>NC(CC(=O)NC(CC(=O)NC(CC(=O)O)C(=O)NC(CC(=O)O)C(=O)O)C(=O)O)C(=O)O</smiles>

c

Figure 3. Molecular structures of 2-phosphonbutane-1,2,4-tricarboxylic acid (PBTCA) (a), hydroxyethylenediphosphonic acid (HEDP) (b) and polyaspartic acid (PASP) (c).

The differences of molecular structure lead to different precipitation inhibition performances. According to the static scale inhibition tests, the inhibition rates of the synthesized polymer on calcium sulfate and calcium carbonate are better than those of EDTA, DEA, hydroxyethylenediphosphonic acid (HEDP), 2-phosphonbutane-1,2,4-tricarboxylic acid (PBTCA), polyaspartic acid (PASP) and the 
compound (the combination of two monomers) (as shown in Figure 4A). The little molecule compounds, EDTA, DEA or the combination of monomers, are not suitable inhibitors for calcium sulfate scale, because the scale inhibition rate is still less than $10 \%$ even when the dosage is $25 \mathrm{mg} / \mathrm{L}$. Although the inhibition rate of $25 \mathrm{mg} / \mathrm{L}$ PBTCA is up to $50 \%$ on the calcium sulfate scale, it is not as functional an inhibitor as the polymer. This is due to the fact the carboxyl group, ester bond and amide bond have scale inhibition effects on calcium sulfate and can chelate with calcium ion, making it difficult to form scale. After adding a scale inhibitor, the scale inhibition performance has not been obviously improved. Although test conditions are different, similar test results $[26,35,36]$ were obtained.

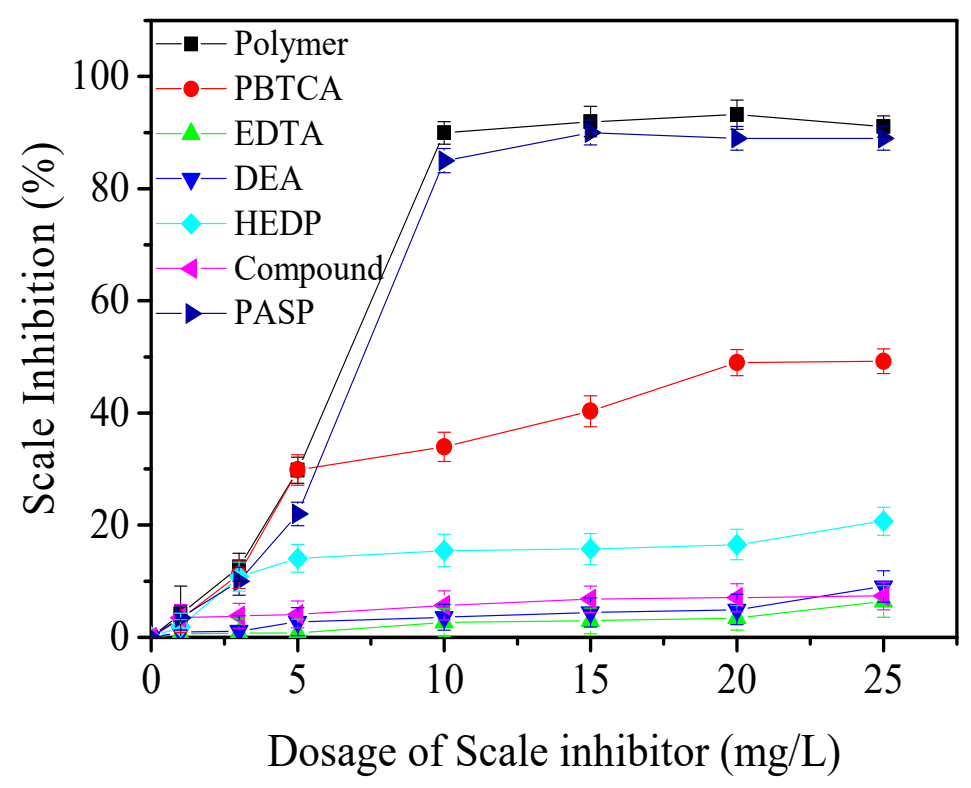

(A)

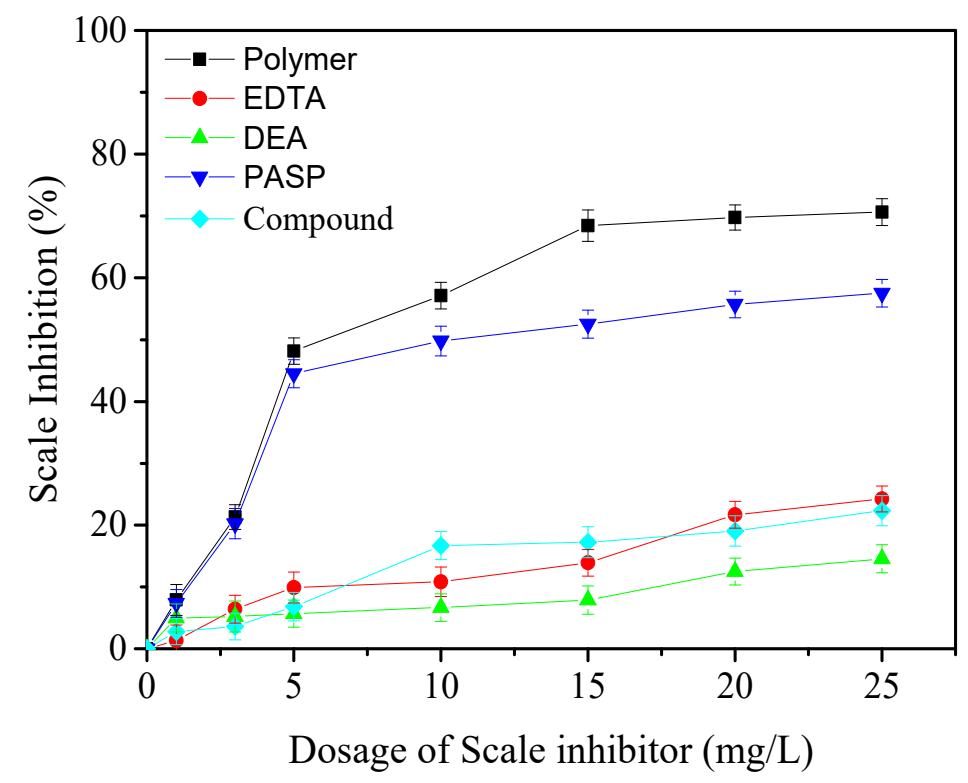

(B)

Figure 4. Precipitation inhibition performances of polymer, the commercial scale inhibitor and monomer on calcium sulfate (A), and calcium carbonate (B). 
Compared with other inhibitors, the scale inhibition effect of the synthesized polymer on calcium carbonate is inclined to be better (refer to Figure 4B). When the polymer concentration is $15 \mathrm{mg} / \mathrm{L}$, the precipitation inhibition rate can reach about $70 \%$. Therefore, diethylenediamine tetraacetate diethanolamine is a kind of polymer with inhibition on calcium sulfate and calcium carbonate precipitation.

\subsection{Different Conditions of Inhibition Test}

The initial $\mathrm{Ca}^{2+}$ concentration in the solution also has influences on the precipitation inhibition performance of prepared polymers against calcium sulfate. As the calcium ion concentration increases, the inhibition rate decreases. Figure $5 \mathrm{~A}$ reveals the inhibition of the polymer against calcium sulfate at different initial $\mathrm{Ca}^{2+}$ concentrations. It can be found that when the $\mathrm{Ca}^{2+}$ concentration is $2040 \mathrm{mg} / \mathrm{L}$, the scale inhibition effect of the polymer achieves the best performance. When the polymer concentration is $3 \mathrm{mg} / \mathrm{L}$, the scale inhibition rate reaches $89.58 \%$. As the calcium ion concentration increases, the inhibitor effect of the polymer becomes worse. However, when the calcium ion concentration is $4000 \mathrm{mg} / \mathrm{L}$ and the amount of polymer is $25 \mathrm{mg} / \mathrm{L}$, the scale inhibition rate can also reach $55.6 \%$.

With the rise of the concentration of calcium ions, the probability of collision and recombination between calcium ions and sulfate ions increases, the precipitation is easier to appear, and the inhibition effect weakens.

The inhibition performance of polymers on calcium sulfate precipitation is affected by the heating time of the water bath, as shown in Figure 5B. The inhibition rates of the polymer were determined at $6 \mathrm{~h}, 10 \mathrm{~h}, 14 \mathrm{~h}, 24 \mathrm{~h}$ and $36 \mathrm{~h}$, and did not change much at different water bath times. When the polymer concentration is $10 \mathrm{mg} / \mathrm{L}$, its scale inhibition rate reaches $90 \%$. It can be considered that the synthetic polymer scale inhibitor possesses a strong ability to chelate calcium ions. The calcium ions' precipitation from the solution was still delayed despite the increase of heating time. The results show that the effect of heating time in the water bath on the polymer is small, so that it can inhibit the precipitation of calcium sulfate for a long time.

Temperature is a significant factor affecting precipitation inhibition efficiency. Figure 5C demonstrates the inhibition performance of polymer precipitation inhibitor on calcium sulfate when the water bath temperature is differently set at $50^{\circ} \mathrm{C}, 80^{\circ} \mathrm{C}, 120^{\circ} \mathrm{C}, 150{ }^{\circ} \mathrm{C}$ and $180^{\circ} \mathrm{C}$.

With the temperature of the water bath increasing, the precipitation inhibition performance of precipitation inhibitor against calcium sulfate is getting worse (according to Figure 5C). When the temperature of the water bath rises, the movement of the molecules will become more intense. The probability that calcium ions collide with the sulfate ions will also increase, so that the precipitation will be formed more easily. As a result, the effect of precipitation on calcium sulfate becomes worse and worse. 


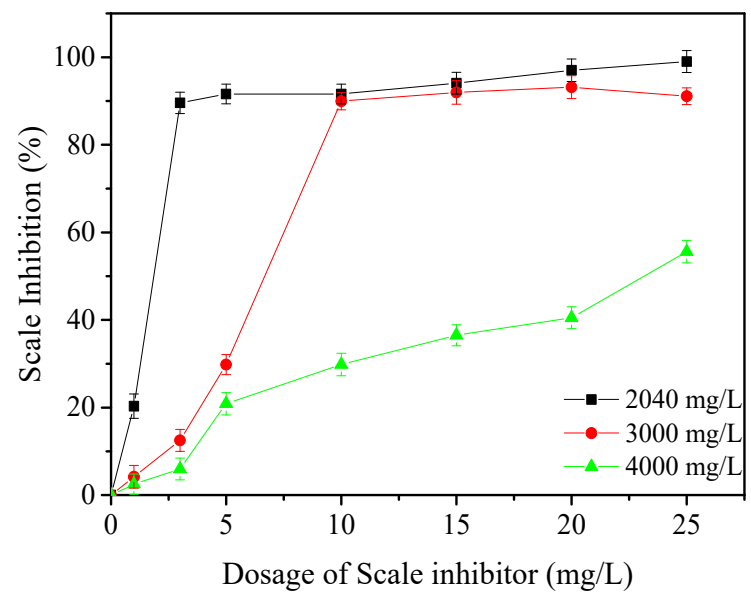

(A)

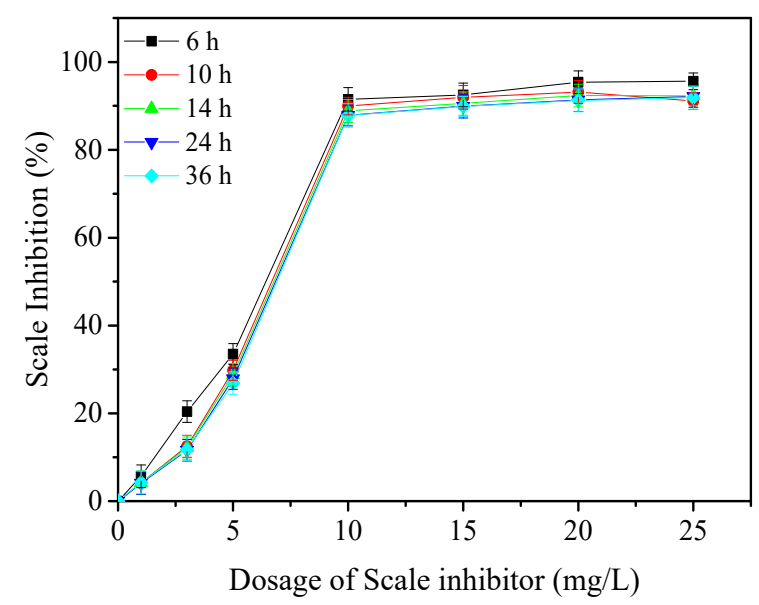

(B)

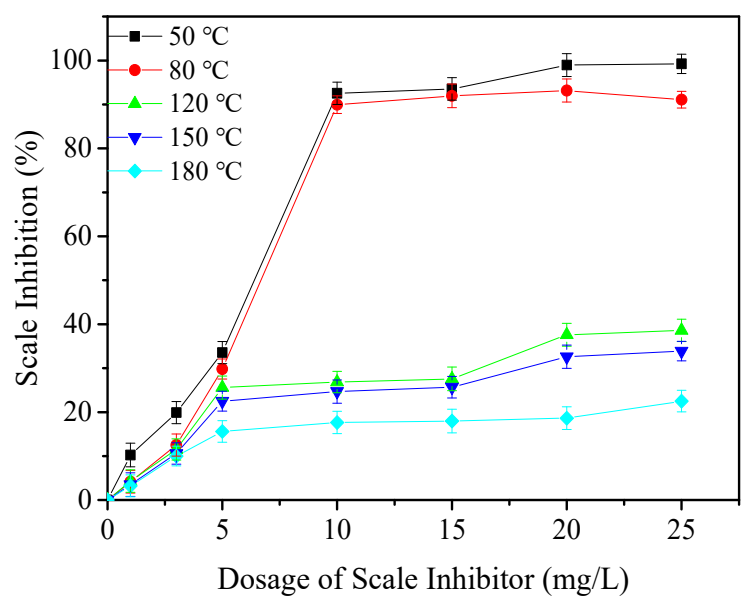

(C)

Figure 5. Precipitation inhibition performances of PEDTA-DEA on calcium sulfate under different initial calcium ion concentrations (A), (in which bath time is $10 \mathrm{~h}$ and temperature is $80^{\circ} \mathrm{C}$ ), different water bath time (B), (in which initial calcium ion concentration is $3000 \mathrm{mg} / \mathrm{L}$ and temperature is $80^{\circ} \mathrm{C}$ ), different water bath temperature (C), (in which initial calcium ion concentration is $3000 \mathrm{mg} / \mathrm{L}$ and bath time is $10 \mathrm{~h}$ ). 


\subsection{Characterization and Analysis of Calcium Sulfate Precipitate}

The precipitation of $\mathrm{CaSO}_{4}$ prepared by adding different doses of precipitation inhibitor is compared with that without precipitation inhibitor. The changes of crystal morphology are manifested in Figure 6.

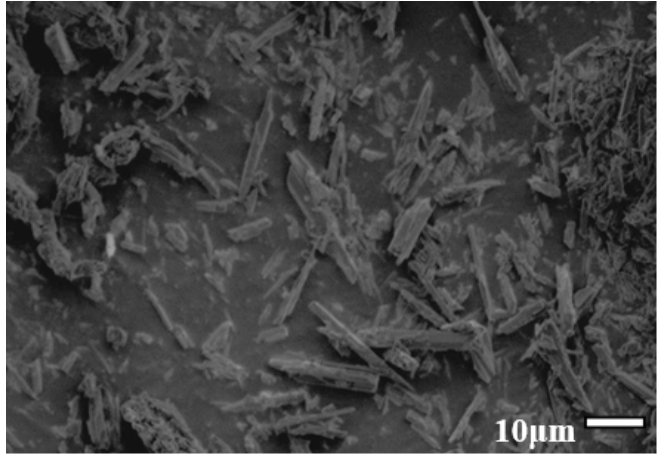

(a)

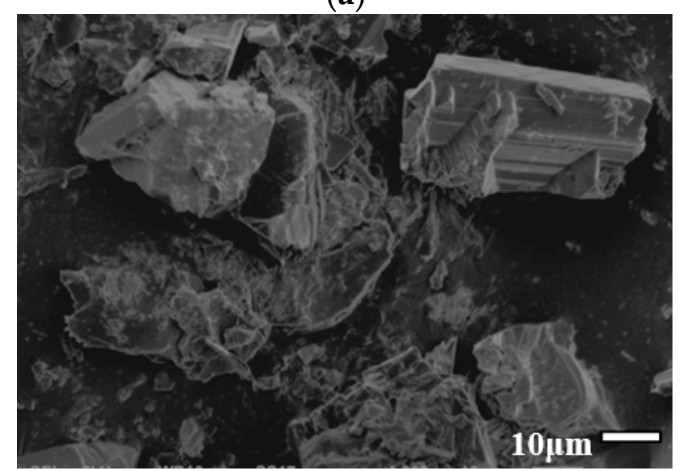

(c)

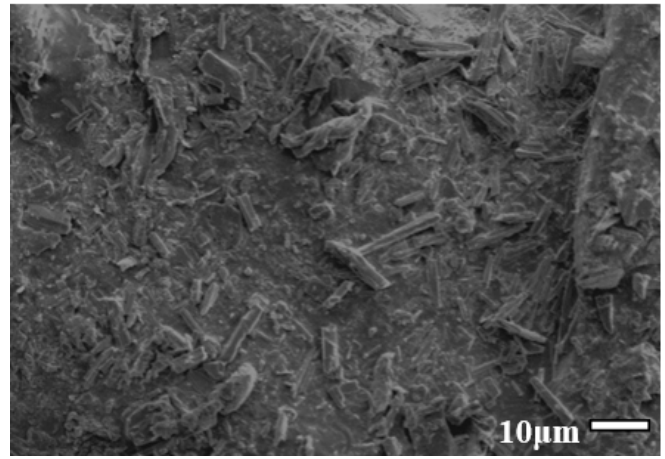

(b)

Figure 6. Morphology of $\mathrm{CaSO}_{4}$ crystals obtained from blank solution (a), solution with $10 \mathrm{mg} / \mathrm{L}$ (b) and $15 \mathrm{mg} / \mathrm{L}$ (c) PEDTA-DEA. All of the solutions are heated to $80{ }^{\circ} \mathrm{C}$ and kept for $10 \mathrm{~h}$.

Most of the $\mathrm{CaSO}_{4}$ precipitation particles without polymer inhibitor are slim and tenuous. The surface of the needle-like precipitation is flat and smooth. With the addition of the polymer inhibitor, the originally smooth surface becomes irregular and needle-like precipitation becomes wide and thick. When the dosage of precipitation inhibitor increases, the surface of the $\mathrm{CaSO}_{4}$ precipitation particles becomes uneven and many defects appear. The crystal also changes from a regular, long strip to a short, irregular crystal. These changes illustrate that adding precipitation inhibitor has a great influence on the growth process and morphology of $\mathrm{CaSO}_{4}$ crystal [36]. Calcium precipitation added with precipitation inhibitor is more likely to flow with water rather than adhere to the pipeline. There are inevitably solid impurities in the water [37] which will become the nucleation center of gypsum. After adding scale inhibitor, the scale inhibitor will be adsorbed on the surface of solid impurities in the form of calcium salt, thus blocking the nucleation of calcium sulfate and preventing the formation of scale $[37,38]$.

In order to further investigate the calcium sulfate crystal, the precipitation obtained from the static scale inhibition experiment was subjected to XRD testing. The diffraction patterns of calcium sulfate crystals with and without the inhibitor are shown in Figure 7. 


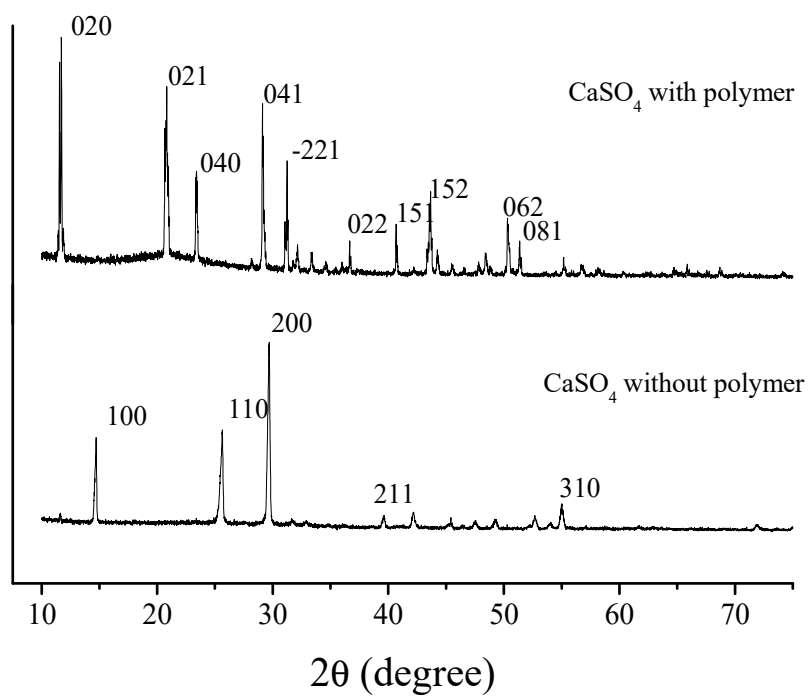

Figure 7. X-ray diffraction pattern of $\mathrm{CaSO}_{4}$ crystals obtained from blank solution and solutions with $10 \mathrm{mg} / \mathrm{L}$ polymer inhibitors.

In the absence of precipitation inhibitor, the diffraction peaks are mainly distributed at $14.7^{\circ}$, $25.6^{\circ}$ and $29.7^{\circ}$, which are the diffraction peaks of calcium sulfate crystals lattice planes of (100), (110) and (200), respectively. After adding polymer inhibitor, the main diffraction peaks appear at $11.6^{\circ}, 20.7^{\circ}, 23.4^{\circ}, 29.1^{\circ}$ and $31.1^{\circ}$, corresponding to lattice faces of (020), (021), (040) (041) and (-221) of gypsum (syn) $[39,40]$. What is mentioned above indicates that the polymer has altered the crystal type of calcium sulfate precipitation.

The calcium sulfate precipitation is characterized by infrared spectroscopy (shown in Figure 8).

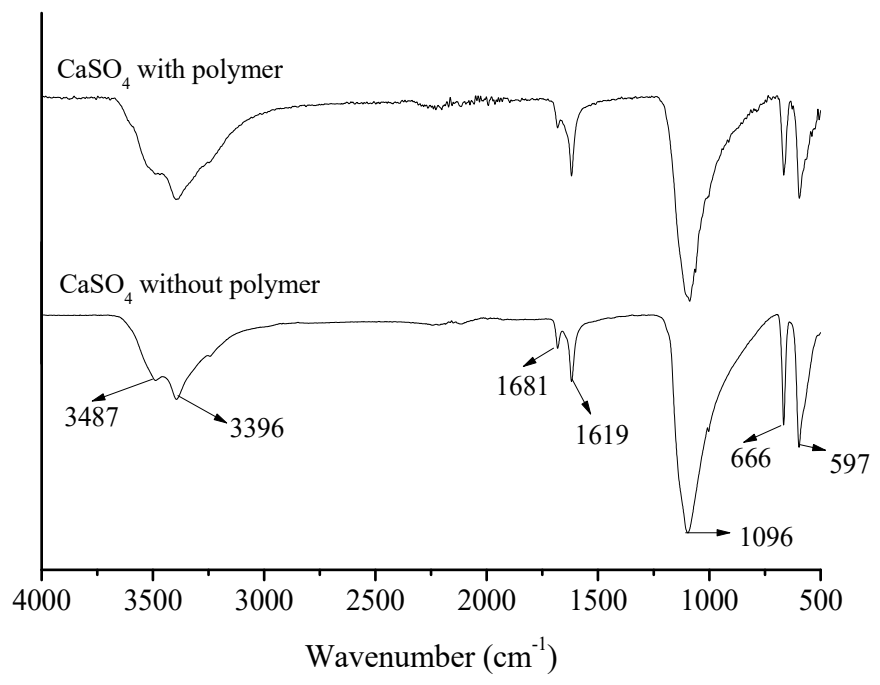

Figure 8. FTIR spectra of $\mathrm{CaSO}_{4}$ precipitation obtained from blank solution and solutions with polymer inhibitor.

The infrared absorption peak of calcium sulfate precipitation mainly appearing at $3487 \mathrm{~cm}^{-1}$, $3396 \mathrm{~cm}^{-1}$ and the peak at $1681 \mathrm{~cm}^{-1}$ are the stretching vibration peaks of the hydroxyl group, the peaks at $666 \mathrm{~cm}^{-1}$ and $597 \mathrm{~cm}^{-1}$ represent the stretching and bending vibration of sulfate, the peak at $1096 \mathrm{~cm}^{-1}$ is the stretching vibration of S-O and the peak at $1619 \mathrm{~cm}^{-1}$ is the stretching vibration of $\mathrm{S}=\mathrm{O}$ [41,42]. If we choose the intensity of absorption peaks at $1096 \mathrm{~cm}^{-1}$ (I1096) as standard, the intensities of absorption peaks at $1681 \mathrm{~cm}^{-1}, 666 \mathrm{~cm}^{-1}$ and $597 \mathrm{~cm}^{-1}$ will obviously become weaker, while the intensities of absorption peaks at $3487 \mathrm{~cm}^{-1}, 3396 \mathrm{~cm}^{-1}$ and $1619 \mathrm{~cm}^{-1}$ will be stronger. 
Compared with the hydroxyl vibration peak of calcium sulfate, the tendency of hydroxylation is strong, which indicates that the crystal form of calcium sulfate has changed [43]. This is also consistent with the results of the XRD.

As mentioned above, the crystal structure of the calcium sulfate precipitation can be significantly changed by adding the polymer inhibitor. That is the lattice distortion caused by the polymer inhibitor in the precipitation formation process. The polymer molecules adsorbing to the surface of the $\mathrm{CaSO}_{4}$ crystals not only hinder the growth of $\mathrm{CaSO}_{4}$ crystals but also make the crystal structure unstable and distorted, causing the formed $\mathrm{CaSO}_{4}$ precipitation to be easily washed away.

\section{Conclusions}

PEDTA-DEA was successfully synthesized by a thermal polycondensation reaction with EDTA and DEA as monomers. The synthesis conditions for PEDTA-DEA are 1:1 monomer molar ratio of EDTA to DEA, $200^{\circ} \mathrm{C}$ polymerization temperature and $2 \mathrm{~h}$ for a reaction. The polymer produces excellent inhibition effect on calcium sulfate precipitation. According to the static test, when $\mathrm{Ca}^{2+}$ concentration is $3000 \mathrm{mg} / \mathrm{L}$, and the amount of the polymer inhibitor is $10 \mathrm{mg} / \mathrm{L}$, the inhibition rate exceeds $90 \%$. Considering that the scale inhibition rate increases with the growth of polymer concentration, and that the polymer inhibitor can apparently distort the precipitation crystal structure and impact on it, based on the results of SEM, XRD and FTIR. Consequently, the polymer PEDTA-DEA is prepared as a kind of potential precipitation inhibitor against calcium sulfate crystal.

Author Contributions: Y.-Z.Z.: conceptualization, funding acquisition, methodology, project administration, preparation of manuscripts; J.-Q.C.: data curation, formal analysis, original draft writing; T.-R.L. and M.-M.S.: validation; H.-H.G.: funding acquisition, theoretical and technical adviser. All authors have read and agreed to the published version of the manuscript.

Funding: This work was supported by the Technology Commission of Shanghai Municipality (Grant Nos. 17dz2282800).

Acknowledgments: The authors acknowledge the financial support of Science and Technology Commission of Shanghai Municipality (Nos. 17dz2282800).

Conflicts of Interest: The authors declare no conflict of interest.

\section{References}

1. Rahmani, K.; Jadidian, R.; Haghtalab, S. Evaluation of inhibitors and biocides on the corrosion, scaling and biofouling control of carbon steel and copper-nickel alloys in a power plant cooling water system. Desalination 2015, 393, 174-185. [CrossRef]

2. Kavitha, A.L.; Vasudevan, T.; Prabu, H.G. Evaluation of synthesized antiscalants for cooling water system application. Desalination 2011, 268, 38-45. [CrossRef]

3. Touir, R.; Cenoui, M.; Bakri, M.E.; Touhami, M.E. Sodium gluconate as corrosion and scale inhibitor of ordinary steel in simulated cooling water. Corros. Sci. 2008, 50, 1530-1537. [CrossRef]

4. Chauhan, K.; Kumar, R.; Kumar, M.; Sharma, P.; Chauhan, G.S. Modified pectin-based polymers as green antiscalants for calcium sulfate scale inhibition. Desalination 2012, 305, 31-37. [CrossRef]

5. Zhao, Y.; Xu, Z.M.; Wang, B.B.; He, J.J. Scale inhibition performance of sodium carboxymethyl cellulose on heat transfer surface at various temperatures: Experiments and molecular dynamics simulation. Int. J. Heat Mass Trans. 2019, 141, 457-463. [CrossRef]

6. Liu, F.; Lu, X.; Yang, W.; Lu, J.J.; Zhong, H.Y.; Chang, X.; Zhao, C.C. Optimizations of inhibitors compounding and applied conditions in simulated circulating cooling water system. Desalination 2013, 313, 18-27. [CrossRef]

7. Ou, H.H.; Tran, Q.T.P.; Lin, P.H. A synergistic effect between gluconate and molybdate on corrosion inhibition of recirculating cooling water systems. Corros. Sci. 2018, 133, 231-239. [CrossRef]

8. Zhang, S.P.; Qu, H.J.; Yang, Z.; Fu, C.E.; Tian, Z.Q.; Yang, W.B. Scale inhibition performance and mechanism of sulfamic/amino acids modified polyaspartic acid against calcium sulfate. Desalination 2017, 419, 152-159. [CrossRef] 
9. Rahardianto, A.; Shih, W.Y.; Lee, R.W.; Cohen, Y. Diagnostic characterization of gypsum scale formation and control in RO membrane desalination of brackish water. J. Membr. Sci. 2006, 279, 655-668. [CrossRef]

10. Fu, L.P.; Lv, J.; Zhou, L.; Li, Z.D.; Tang, M.J.; Li, J.B. Study on corrosion and scale inhibition mechanism of polyaspartic acid grafted $\beta$-cyclodextrin. Mater. Lett. 2020, 264, 127-276.

11. Shakkthivel, P.; Vasudevan, T. Acrylic acid-diphenylamine sulphonic acid copolymer threshold inhibitor for sulphate and carbonate scales in cooling water systems. Desalination 2006, 197, 179-189. [CrossRef]

12. Shi, W.Y.; Ding, C.; Yan, J.L.; Han, X.Y.; Lv, Z.M.; Lei, W.; Xia, M.Z.; Wang, F.Y. Molecular dynamics simulation for interaction of PESA and acrylic copolymers with calcite crystal surfaces. Desalination 2012, 291, 8-14. [CrossRef]

13. Senthilmurugan, B.; Ghosh, B.; Kundu, S.S.; Haroun, M.; Kameshwari, B. Maleic acid-based scale inhibitors for calcium sulfate scale inhibition in high temperature application. J. Petrol. Sci. Eng. 2010, 75, 189-195. [CrossRef]

14. Amjad, Z.; Koutsoukos, P.G. Evaluation of maleic acid-based polymers as scale inhibitors and dispersants for industrial water applications. Desalination 2014, 335, 55-63. [CrossRef]

15. Wang, T.; Zhao, C.H.; Xu, J.; Sun, D.J. Enhanced $\mathrm{Ca}^{2+}$ binding with sulfonic acid type polymers at increased temperatures. Colloids Surf. A Physicochem. Eng. Asp. 2013, 417, 256-263. [CrossRef]

16. Yang, L.; Yang, W.Z.; Xu, B.; Yin, X.S.; Chen, Y.; Liu, Y.; Ji, Y.; Huan, Y. Synthesis and scale inhibition performance of a novel environmentally friendly and hydrophilic terpolymer inhibitor. Desalination 2017, 416, 166-174. [CrossRef]

17. Jensen, M.K.; Kelland, M.A. A new class of hyper branched polymeric scale inhibitors. J. Petrol. Sci. Eng. 2012, 94, 66-72. [CrossRef]

18. Ou, H.H.; Hsieh, L.H.C. A synergistic effect of sodium gluconate and 2-phosphonobutane-1, 2, 4-tricarboxylic acid on the inhibition of $\mathrm{CaCO}_{3}$ scaling formation. Powder Technol. 2016, 302, 160-167. [CrossRef]

19. Khormali, A.; Sharifov, A.R.; Torba, D.I. Increasing efficiency of calcium sulfate scale prevention using a new mixture of phosphonate scale inhibitors during water flooding. J. Petrol. Sci. Eng. 2018, 164, 245-258. [CrossRef]

20. Klepetsanis, P.G.; Koutsoukos, P.G. Kinetics of calcium sulfate formation in aqueous media: Effect of organ phosphorus compounds. J. Cryst. Growth 1998, 193, 156-163. [CrossRef]

21. Migahed, M.A.; Rashwan, S.M.; Kamel, M.M.; Habib, R.E. Synthesis, characterization of polyaspartic acid-glycine adduct and evaluation of their performance as scale and corrosion inhibitor in desalination water plants. J. Mol. Liq. 2016, 224, 849-858. [CrossRef]

22. Gao, Y.H.; Fan, L.H.; Ward, L.; Liu, Z.F. Synthesis of polyaspartic acid derivative and evaluation of its corrosion and scale inhibition performance in seawater utilization. Desalination 2015, 365, 220-226. [CrossRef]

23. Zhang, Y.; Yin, H.Q.; Zhang, Q.S.; Li, Y.Z.; Yao, P.J. Synthesis and characterization of novel polyaspartic acid/urea graft copolymer with acylamino group and its scale inhibition performance. Desalination 2016, 395, 92-98. [CrossRef]

24. Huang, H.H.; Yao, Q.; Jiao, Q.; Liu, B.L.; Chen, H.L. Polyepoxysuccinic acid with hyper-branched structure as an environmentally friendly scale inhibitor and its scale inhibition mechanism. J. Saudi Chem. Soc. 2019, 23, 61-74. [CrossRef]

25. Liu, D.; Dong, W.B.; Li, F.T.; Hui, F.; Lédion, J. Comparative performance of polyepoxysuccinic acid and polyaspartic acid on scaling inhibition by static and rapid controlled precipitation methods. Desalination 2012, 304, 1-10. [CrossRef]

26. Zhao, Y.Z.; Jia, L.L.; Liu, K.Y.; Gao, P.; Ge, H.H.; Fu, L.J. Inhibition of calcium sulfate scale by poly (citric acid). Desalination 2016, 392, 1-7. [CrossRef]

27. Evstatiev, R.; Cervenka, A.; Lang, M.; Frick, A.P.; Gmainer, C.; Krnjic, A.; Khare, V.; Gasche, C. EDTA compounds, as used in food additives, aggravate intestinal inflammation and drive tumorigenesis in a mouse model of colitis-associated cancer. Gastroenterology 2017, 152, S735. [CrossRef]

28. Evstatiev, R.; Deim, G.; Khare, V.; Gmainer, C.; Krnjic, A.; Cervenka, A.; Lang, M.; Baumgartner, M.; Frick, A.P.; Gasche, C. The food additive EDTA increases intestinal inflammation and colorectal carcinogenesis by disrupting the intestinal epithelial barrier. Z. Gastroenterol. 2019, 57, V05.

29. Ying, C.; Chen, X.S.; Liang, Y.N. Synthesis of polyaspartic acid/graphene oxide grafted copolymer and evaluation of scale inhibition and dispersion performance. Diam. Relat. Mater. 2020, 108, 107949. 
30. Dayarathne, H.N.P.; Jeong, S.; Jang, A. Chemical-free scale inhibition method for seawater reverse osmosis membrane process: Air micro-nano bubbles. Desalination 2019, 461, 1-9. [CrossRef]

31. Benecke, J.; Haas, M.; Baur, F.; Ernst, M. Investigating the development and reproducibility of heterogeneous gypsum scaling on reverse osmosis membranes using real-time membrane surface imaging. Desalination 2018, 428, 161-171. [CrossRef]

32. Amjad, Z. Kinetic and morphological investigation of calcium sulfate dihydrate (gypsum) scale formation on heat exchanger surfaces in the presence of inhibitors. Int. J. Corros. Scale Inhib. 2017, 6, 276-290.

33. Roomi, Y.A.; Hussein, K.F.; Riazi, M.R. Inhibition efficiencies of synthesized anhydride based polymers as scale control additives in petroleum production. J. Petrol. Sci. Eng. 2012, 81, 151-160. [CrossRef]

34. Chaúque, E.F.C.; Ngila, J.C.; Ray, S.C.; Ndlwana, L. Degradation of methyl orange on Fe/Ag nanoparticles immobilized on polyacrylonitrile nanofibers using EDTA chelating agents. J. Environ. Manag. 2019, 236, 481-489. [CrossRef]

35. Liu, Y.; Zhou, Y.; Yao, Q.; Huang, J.; Liu, G.; Wang, H.; Cao, K.; Chen, Y.; Bu, Y.; Wu, W.; et al. Double-hydrophilic polyether antiscalant used as a crystal growth modifier of calcium scales in cooling-water systems. J. Appl. Polym. Sci. 2014, 131, 39792. [CrossRef]

36. Li, H.Y.; Ma, W.; Wang, L.; Liu, R.; Wei, L.S.; Wang, Q. Inhibition of calcium and magnesium-containing scale by a new antiscalant polymer in laboratory tests and a field trial. Desalination 2006, 196, 237-247. [CrossRef]

37. Oshchepkov, M.S.; Kamagurov, S.; Tkachenko, S.; Popov, K.; Ryabova, A. An Insight into the Mechanisms of the Scale Inhibition. A Case Study of a Novel Task-specific Fluorescent-tagged Scale Inhibitor Location on Gypsum Crystals. ChemNanoMat 2019, 5, 586-592. [CrossRef]

38. Popov, K.; Rudakova, G.; Larchenko, V.; Tusheva, M.; Kamagurov, S.; Dikareva, J.; Kovaleva, N. A Comparative Performance Evaluation of Some Novel "Green" and Traditional Antiscalants in Calcium Sulfate Scaling. Adv. Mat. Sci. Eng. 2016, 2016, 1-10. [CrossRef]

39. Zhang, B.; Zhou, D.P.; Lv, X.G.; Xu, Y.; Cui, Y.C. Synthesis of polyaspartic acid/3-amino-1H-1,2,4-triazole5 -carboxylic acid hydrate graft copolymer and evaluation of its corrosion inhibition and scale inhibition performance. Desalination 2013, 327, 32-38. [CrossRef]

40. Inoue, M.; Hirasawa, I. The relationship between crystal morphology and XRD peak intensity on $\mathrm{CaSO}_{4} \cdot 2 \mathrm{H}_{2} \mathrm{O}$. J. Cryst. Growth 2013, 380, 169-175. [CrossRef]

41. Silva, A.M.; Junot, D.O.; Caldas, L.V.; Souza, D.N. Structural, optical and dosimetric characterization of $\mathrm{CaSO}_{4}: \mathrm{Tb}, \mathrm{CaSO}_{4}: \mathrm{Tb}, \mathrm{Ag}$ and $\mathrm{CaSO}_{4}: \mathrm{Tb}, \mathrm{Ag}(\mathrm{NP})$. J. Lumin. 2020, 224, 117286. [CrossRef]

42. Böke, H.; Akkurt, S.; Özdemir, S.; Göktürk, E.H.; Saltik, E.N.C. Quantification of $\mathrm{CaCO}_{3}-\mathrm{CaSO}_{3} 0.5$ $\mathrm{H}_{2} \mathrm{O}-\mathrm{CaSO}_{4} \cdot 2 \mathrm{H}_{2} \mathrm{O}$ mixtures by FTIR analysis and its ANN model. Mater. Lett. 2004, 58, 723-726. [CrossRef]

43. Wang, Y.B. Study on the surface properties and hydration meehanism of calcium sulfate whiskers. Ind. Miner. Process. 2008, 6, 1-4.

(C) 2020 by the authors. Licensee MDPI, Basel, Switzerland. This article is an open access article distributed under the terms and conditions of the Creative Commons Attribution (CC BY) license (http://creativecommons.org/licenses/by/4.0/). 